\title{
ALEGORÍA Y COMICIDAD EN EL AUTO SACRAMENTAL DE ALONSO DE CASTILLO SOLÓRZANO EL FUEGO DADO DEL CIELO
}

\author{
Belinda Palacios \\ Université de Genève \\ belinda.palacios@unige.ch
}

$\mathrm{P}$ ese a haber sido un prolífico novelista, la obra dramática de Castillo Solórzano es más bien modesta, y El fuego dado del cielo parece ser su único auto sacramental. Hasta la fecha, se conocen dos ejemplares del auto, ambos conservados en la Biblioteca Nacional de España, en Madrid. Según el estudio de Gabriel Maldonado Palmero, el más antiguo (signatura Mss/15245) parece ser un autógrafo del propio Castillo Solórzano. A este manuscrito le faltan algunas hojas, puesto que se produce un salto del verso 994 al 1109. Se asume entonces que la numeración de las mismas es posterior, pues no toma en cuenta este salto (Maldonado Palmero 2000: 61).

El segundo ejemplar que se conoce sí nos ha llegado completo y se encuentra en el interior de un volumen manuscrito titulado Autos de diferentes ingenios, conjunto que parece datar del siglo XVIII (signatura Mss/14773). El auto de Castillo Solórzano es el segundo en este tomo, que contiene, asimismo, autos de Calderón, uno de Lope, otro de Tirso de Molina, etc., y cinco loas sacramentales. Además de recoger los 165 versos faltantes en el primer manuscrito, este ejemplar presenta también algunas leves variantes con respecto al texto original, algo que Maldonado Palmero atribuye a la falta de atención del copista ${ }^{1}$.

\footnotetext{
Cabe resaltar que el texto ha sido editado solo dos veces: la primera en 1974 por Franco Bacchelli, y la segunda en el año 2000 por Gabriel Maldonado Palmero. Dado que ambas ediciones presentan algunas diferencias, hemos decidido trabajar con la de Maldonado Palmero (Castillo 2000), por ser la más reciente, y porque recoge también las variantes con respecto a la edición de Bacchelli. Los estudiosos tampoco coinciden con la fecha de composición del auto: mientras que para Bacchelli esta debe situarse alrededor de 1635-1636, Maldonado la establece entre 1641 y 1642, presentándola como una de sus últimas obras (Maldonado Palmero 2000: 61-63).
}

Edad de Oro, XXXVI (2017), pp. 123-134, ISSN: $0212-0429$ - DOI http://dx.doi.org/10.15366/edadoro2017.36.008 
Presentamos estos datos como información preliminar, pues el objetivo de este artículo no es hacer un estudio crítico de la edición del texto, sino un análisis de su contenido y, más precisamente, de la manera en que funciona en él la alegoría. Así, comentaremos la forma en la que Castillo Solórzano recurre a la comicidad en el auto con fines alegóricos y didácticos, convirtiéndola, en palabras de Reiner Hess, en la «plasmación escénica de la doctrina cristiana» (Hess 1976: 268).

La obra comienza cuando Ciro, rey de Persia, vence a Baltasar y se apodera de la ciudad de Babilonia, cumpliendo el vaticinio del profeta Daniel. Ciro conoce al profeta y decide liberar a los hebreos para que vuelvan a sus tierras, pero le pide que se quede gobernando con él en Babilonia, junto con algunos judíos más. A partir de este momento, la acción en el auto se divide en dos: tenemos por una parte la historia de las tribus de Israel que regresan a Judea con el rey Nehemías y por la otra, lo que acontece en la corte del rey Ciro.

En cuanto a la primera, la acción se centra en buscar y recuperar el fuego sagrado que los hebreos habían ocultado antes de partir a Babilonia, símbolo de su alianza con Dios. En la corte, sin embargo, las cosas son un poco más complejas, pues cuando Ciro conoce a Florinda, la viuda de Baltasar, se enamora de ella, lo que provoca los celos de su mujer, así como una suerte de enredo amoroso en el que nos detendremos más adelante. Este asunto se verá resuelto por el trágico destino que le espera a Ciro. Luego de escuchar una profecía que le advierte que morirá decapitado por Tomisiris, la reina amazona, Ciro decide ir a enfrentarse con ella, pero antes permite a Daniel regresar con el resto de judíos a sus tierras y acepta la unión de Darío con Florinda.

El auto concluye con el regreso de Daniel junto a los suyos, tras lo cual se produce un prodigio: «en lo alto se descubre un niño con unas brasas en la mano y cinco rayos de luz» (Castillo 2000: 187). Daniel explica entonces que aquel niño representa al Mesías y que el fuego que lleva en sus manos simboliza su inmensa caridad. A propósito del final, Maldonado Palmero indica que «estos versos finales son los que mejor explican el motivo fundamental del auto -solo indicado de forma simbólica en el título. La caridad divina siempre estará presente para con el hombre pecador» (2000: 66). Esta afirmación, aunque cierta, nos parece algo insuficiente para explicar la forma en la que se manifiesta (y se hace drama) la alegoría en este auto sacramental.

Volvamos entonces al principio. La obra de Castillo Solórzano es claramente un auto sacramental de argumento bíblico: su trama procede (en gran medida) de episodios del Antiguo Testamento: del Libro de las Crónicas, de Esdras, del Libro de Daniel; e incluso, como bien señala Maldonado Palmero (2000: 95-96), constatamos que Castillo Solórzano prácticamente transcribe partes de II Macabeos 1,18 para componer la carta que le envía Nehemías a Daniel, contando que han recuperado el fuego sagrado. El recurrir a episodios bíblicos para componer 
el asunto del auto sacramental fue bastante común, puesto que se tenía como algo admitido desde los inicios del cristianismo que el Antiguo Testamento prepara y prefigura el nuevo. De esta manera, muchos de sus pasajes son comprendidos como anunciadores de la venida de Cristo, símbolo de la nueva alianza con Dios (Flecniakoska 1961: 350). Esto es lo que explica que, a primera vista, pareciera que el auto no presenta ningún personaje alegórico en el sentido clásico del término: como se puede apreciar tras consultar la lista de los diecisiete personajes que participan en la pieza, todos ellos son seres humanos. Sin embargo, veremos a continuación cómo estos funcionan en la práctica como personajes alegóricos, y sus actos y palabras han de ser comprendidos también de esta forma ${ }^{2}$. No hay que olvidar que, aunque el argumento haya sido extraído del Antiguo Testamento, el asunto del auto (es decir, el tema de fondo, sobre el cual se cimienta la alegoría) está situado en el presente, pues tiene como objetivo el celebrar la Eucaristía (Flecniakoska 1961: 407).

Como la acción en el auto se divide en dos partes bien delimitadas (el desierto y la corte), hemos optado por dividir el análisis de la misma manera, centrando nuestra atención en los personajes de Ciro y Zabulón, por ser aquellos que protagonizan a su vez los momentos de comicidad en cada parte del auto. Comencemos con Ciro. Para Maldonado Palmero, el personaje de Ciro funciona como mediador entre la escena y el público, permitiendo (a través de las preguntas que le hace a Daniel sobre su fe) ilustrar al auditorio sobre las verdades del dogma y las sagradas escrituras. Más adelante, concluye al respecto que «Ciro aparece como el personaje que tiene como única misión la de ser el que libera del cautiverio al pueblo judío» (2000: 98). Esto me parece un poco reductor, pues deja de lado el componente de «enseñanza moral» que se esperaba de la utilización de temas provenientes del Antiguo Testamento (Flecniakoska, 1961:350).

$\mathrm{Si}$ bien es cierto que la primera parte del auto se abre con algunas intervenciones del abuelo de Ciro y luego un largo juego de preguntas y respuestas entre Ciro y Daniel, estos diálogos juegan un rol más importante que el de solo «ilustrar» al público. En realidad, es gracias a este personaje que el espectador descubre el lugar que ocupa Ciro en la estructura interna del auto, y también el que ocupa él mismo (es decir, el público, el pueblo español) en la economía de la salvación. Los diálogos permiten al espectador comprender que Ciro es el tercero de los gobernantes de Babilonia a los que se les revela la grandeza del Dios de los hebreos, pero que a pesar de reconocer esta grandeza eligen darle la espalda y mantener sus propios cultos y vanidad (los otros dos son Nabucodonosor II, quien manda

2 El tipo de alegoría al que recurre Castillo Solórzano vendría a ser lo que Ignacio Arellano y Enrique Duarte califican de allegoria in factis, es decir, una interpretación simbólica de los sucesos del Antiguo Testamento que permita «explicar el sacramento eucarístico por medio de la exégesis tipológica» (Arellano/ Duarte 2003: 25-26).

Edad de Oro, XXXVI (2017), pp. 123-134, ISSN: 0212-0429 
quemar a tres hebreos que se resisten a adorar la estatua que ha mandado hacer de él mismo, pero que son protegidos por Dios; y Baltasar, su hijo, que comete el sacrilegio de beber de los vasos sagrados del templo de Jerusalén y se resiste a arrepentirse de sus pecados, pese a las advertencias de Daniel). Ambas historias son retomadas al comienzo del auto (vv. 80-97; 131-142), estableciéndose una continuidad entre los tres relatos. Ciro, al igual que los gobernantes anteriores de Babilonia, es testigo tanto de la fidelidad que mantiene Dios para con su pueblo (derrota a los babilonios, mantiene encendido el fuego sagrado a pesar de los años de cautiverio), como del castigo que puede infligir este mismo Dios a quienes se oponen a él. A pesar de esto, Ciro declara hacia el final del auto:

\author{
Dejemos eso ahora \\ que aunque el poder de ese tu Dios no ignora \\ el alma que le ama, \\ a venerar mi religión me llaman \\ las paternas deidades \\ cuanto a la tuya más me persüades. (vv. 1379-1384)
}

Y no solo eso, sino que peca de la misma soberbia que los otros dos: fuerza a Daniel a preguntarle a su Dios sobre su futuro, a pesar de que aquel había intentado disuadirlo (vv. 1532-1571). Finalmente es castigado, pues muere decapitado a manos de una mujer. Comprender el personaje de Ciro como un elemento clave de la historia de la alianza (y por ende, al analizar la decisión de Castillo Solórzano de generar una continuidad entre su historia y la de Nabucodonosor y Baltasar) permite dos enseñanzas fundamentales: la primera, que Dios no se olvida de su pueblo y que seguirá protegiendo a quienes crean en él; y la segunda, que castigará a los que dejen de hacerlo. Pero su participación no acaba acá, pues es Ciro también uno de los protagonistas del «enredo amoroso» del auto, que se inicia en el verso 15 cuando este último compara la belleza de Florencia con la de las diosas más bellas de la Antigüedad clásica:

\author{
¡Oh mi Florinda, que ofreces \\ día al mundo y luz al cielo! \\ Si yo fuera ahora Paris \\ no sé a cuál la diera el premio, \\ pues en competencia os hizo \\ Dios de beldad raro ejemplo. (vv. 15-20)
}

Esta actitud despierta los celos de Rosa, su esposa, que se irán acrecentando a lo largo de la pieza. Sin embargo, Ciro se encuentra tan obnubilado por Florinda que no se da cuenta de ello: 


$\begin{array}{ll}\text { Rosa } & \begin{array}{l}\text { Estimo, aunque lisonjero, } \\ \text { el favor yo de mi parte. }\end{array} \\ \text { Florinda } & \text { Y yo en el alma le he puesto. } \\ \text { Ciro (aparte.) } & \text { (Pluguiera al cielo!) Mi Rosa, } \\ & \text { ¿cómo os va en el nuevo reino? } \\ \text { Rosa } & \text { Si vos sois mi sol, y en él } \\ & \text { a vuestro lado me veo, } \\ & \text { ¿cómo ha de irme? (Aparte.) (Divertido } \\ & \text { en Florinda está). }\end{array}$

Conforme a la cita, Ciro coquetea con ambas mujeres y se emociona con las palabras de Florinda, como se recalca con el «pluguiera al cielo» que el personaje dice en aparte, desconociendo que Rosa ya se ha dado cuenta de su deseo y que sufre por ello. La comicidad del enredo amoroso viene reforzada por los apartes, que establecen una conexión directa entre los personajes y el público, que asiste con gracia a los intentos de Ciro por seducir a Florinda sin que lo advierta su mujer. El público, por su parte, es también sabedor de que Florinda desea a Darío y de que Darío la corresponde, aunque no se atreve a decírselo a su sobrino. La situación aumenta en tensión dramática (y gracia para los presentes) cuando Ciro advierte el interés de Darío por Florinda y, aparte, dice:

Mucho Darío se declara.

Cortar pretendo los cuellos

a afectos recién nacidos

porque no suban al cielo. (vv. 792-795)

Como dice Flecniakoska (1961: 404-405), todos los elementos del auto (personajes y argumento) han de estar al servicio del asunto, y sin embargo acá tenemos un episodio bastante curioso que nos hace pensar en las comedias de enredos. Al respecto, señala Maldonado Palmero:

Atendiendo las palabras de $\mathrm{Ch}$. Aubrun, podríamos trazar un correlato entre dos series de parejas con respecto al ideal amado. Mientras Darío y Ciro, Rosa y Florinda centran todo su interés en al amor humano [...], los dos sacerdotes judíos, Eliazar y Helí, así como Daniel y Nehemías, centran su atención en torno al amor divino, un amor metafísico. Estos dos ideales de amor seguirán paralelos a lo largo del auto, pero en ningún caso llegarán a cruzarse (2000: 76). 
Aunque esta interpretación sea posible, no pensamos que el enredo deba ser interpretado de esta manera. Los críticos en general parecen estar de acuerdo en que, pese a que el auto sacramental va a tomar prestados varios elementos típicos de la comedia ${ }^{3}$, no debe perderse de vista que la situación cómica siempre ha de mantenerse al servicio de la alegoría, o al menos este es el caso en el auto de Castillo Solórzano ${ }^{4}$. Creemos que no es una casualidad que la esposa de Ciro se llame Rosa en la pieza, cuando según Herodoto (que es quien nos cuenta el final de Ciro decapitado y con la cabeza en un odre lleno de sangre, cortesía de la amazona Tomisiris), la esposa se llamaba Casandana (Herodoto 2015: 25).

La rosa es, como se sabe, el símbolo del cáliz que recoge la sangre de Cristo derramada para salvarnos, símbolo de la nueva alianza con Dios que se conmemora el día del Corpus. Y, como sabemos también, existe desde el Antiguo Testamento la idea que el pueblo de Israel contrae nupcias con Dios ${ }^{5}$. En esta línea de pensamiento, podemos aventurarnos a proponer la siguiente hipótesis: el matrimonio de Ciro con Rosa equivale a la alianza que se establece entre Dios y un pueblo. Así, en el auto Dios permite a Ciro vencer a Baltasar y apoderarse de Babilonia, pero una vez en la ciudad conoce a Florinda y sueña (desea, como bien advierte Rosa) dejar a su esposa por ella. Tampoco puede ser casualidad que para la esposa de Baltasar se haya elegido el nombre de Florinda. Dice el texto:

¿La humildad de cualquier flor,

Florinda, has de comparar

a la majestad sin par

de la rosa? (vv. 670- 673)

En nuestra opinión, este enredo amoroso, que se resuelve cuando Ciro parte a encontrar su muerte, ha de ser entendido de dos maneras. La primera es que si aceptamos la idea de que Ciro establece en algún momento él mismo una alianza con Dios (puesto que Dios le permite derrotar a los babilonios a cambio de la liberación de los hebreos), podemos entender su actitud como una prefiguración de lo ocurrirá más adelante con el pueblo judío, que traiciona la alianza pautada con Dios al darle la espalda a su hijo y condenarlo a morir en la cruz. La segunda es que nos permite establecer una relación con los protestantes, que habiendo conocido la

Para Flecniakoska (1961: 311-312), esto va a ser primordial para asegurar la continuidad del auto, salvándolo de desaparecer.

4 Algo similar concluye Víctor García Ruiz (1994) a propósito de los elementos cómicos presentes en los autos de Calderón.

5 La misma idea se trasvasa más adelante al cristianismo, donde se considera que la Iglesia (comunidad) contrae matrimonio con Cristo. Los ejemplos son múltiples en el Nuevo Testamento, especialmente en las cartas de Pablo (por ejemplo Efesios 5:24-27 y 2 Corintios 11:2) y en el Apocalipsis. 
grandeza de Dios (la Rosa, el Cristo), apenas aparece algo nuevo (religiones menores, heréticas, Florinda), se ven tentados a abandonar la verdadera $\mathrm{fe}^{6}$.

En cuanto a lo que ocurre en el desierto, una vez liberados los hebreos, estos van a tratar de encontrar el fuego sagrado, y con ellos va Zabulón (el gracioso), quien se convierte rápidamente en una de las figuras centrales de la obra. Zabulón fue, para el Antiguo Testamento, el patriarca de una de las doce tribus de Israel. Se trata de un personaje bíblico importante, que sin embargo en nuestro auto aparece caracterizado bajo la figura del gracioso. El espectador percibe esta correspondencia desde el momento en que el comediante aparece en escena, pues tenemos la acotación que dice: «Vanse. Sale Zabulón vestido de pobre y graciosamente», entre los vv. 416-417.

Las intervenciones de Zabulón provocan la risa en el público, y el personaje cumple en buena medida el mismo rol que el gracioso de la comedia. Identificamos recursos típicos de la caracterización de este personaje, como la paranomasia, los juegos de palabras, la bravuconería y fanfarronería iniciales que contrastan con una clara cobardía después, la glotonería (el personaje parece solo pensar en comer) y su violencia innata, pues mata a dos guardias persas por tratarlo de «judío», siendo reprendido después por Daniel (vv. 530- 539) 7 .

La presencia de Zabulón en el auto, sin embargo, no es gratuita, ni se justifica como un mero trasvase de los elementos de la comedia al auto sacramental, ni como una distracción graciosa para el público, sino que cumple un rol primordial en el contexto del Siglo de Oro. Y es que, como nos dice Juan Carlos Garrot (2001: 332), a pesar de que la lectura alegórica del Antiguo Testamento permitió su posterior «cristianización», los dramaturgos de la época sentían alguna molestia en representar a los judíos de manera demasiado favorable, puesto que, a pesar de haber sido el pueblo elegido (la prueba de la fidelidad de Dios hacia sus seguidores), no dejaban de ser también los asesinos del hijo de Dios. Garrot (2001: 332-233, 336) propone entonces que esta dicotomía podría solucionarse, en muchos casos, recurriendo a la figura del gracioso, rol que cumple en nuestro auto el judío Zabulón, que funciona como un puente entre los personajes que aparecen calificados como «hebreos» en el texto (el pueblo hebreo, Daniel, Nehemías, Helí...) y Zabulón, el «judío» ${ }^{8}$. De esta manera, cuando Artábanes, capitán persa, habla de Da-

6 Como bien señala Flecniakoska, «si l'auto n'est pas ostensiblement dirigé contre les hérétiques, il ne manque jamais une occasion de les attaquer» (1961: 381). Volveremos más adelante sobre este asunto.

7 El contraste entre ambas actitudes en el personaje de Zabulón es bastante evidente. Frente a la seguridad que parece profesar hacia su fe después de asesinar a los guardias $-\ll$ Si en desprecio del gran Dios / de Israel vieras hacer / cuatro mil supercherías, / ¿qué hicieras tú?» (vv. 535538)-, resalta el terror que siente de encontrarse frente al fuego sagrado: «Ya voy entrando; / yo pierdo el miedo, mas estoy temblando / y aun pienso se humedecen los calzones» (vv. 931-933).

8 A pesar de que el estudio de Juan Carlos Garrot (2001) se basa en un auto de Calderón bastante

Edad de Oro, XXXVI (2017), pp. 123-134, ISSN: 0212-0429 
niel, lo presenta como «el hebreo» (vv. 98-99), y Florinda, al referirse a los judíos que abandonan la corte, dice: «Pero llega a este balcón / y verás al pueblo hebreo / partirse» (vv. 701-703). Por el contrario, aparece el término «judío» cuando, por ejemplo, un capitán persa dice de Zabulón, luego de apresarlo: «Llevad / a aquese perro judío» (v. 503); o cuando el propio Zabulón, al aludir a su propia tribu, la califica de judía: «Que avise a mi tribu toda / de Zabulón me ha mandado / Daniel [...] y no he de poder buscar / seis judíos en un día» (vv. 417- 425).

Para entender esto, retomo las ideas de Dominique Reyre sobre la oposición terminológica que se opera entre las voces «hebreo» y «judío», puesto que ambas palabras expresan dos miradas distintas sobre ellos, una positiva y una negativa, simbolizando «dos actitudes antinómicas frente al pueblo de Israel» (1998: 14). La estudiosa recuerda que ya desde Covarrubias podemos percibir esta misma oposición léxica. Dice:

Si bien [...] se puede usar cualquiera de los tres vocablos «hebreo, israelita, judío» para «significar el pueblo que Dios llamó como suyo», precisa [...] que el significante «hebreo» y sus afines remiten de manera más general a la antigüedad de los tiempos bíblicos y a «cosas espirituales» [...]. En cambio, «el pueblo que mató al Mesías» está evocado en la entrada de la voz «judío». (1998: 14)

Ahora bien, hay otra razón en la que me baso para afirmar esta intención, y es la que se oculta en el largo discurso de Daniel hacia Ciro, compuesto de 130 versos al inicio del auto, en los que Daniel retoma la historia de la Alianza, desde la creación del hombre y la envidia del Diablo (que el texto califica de ángel presumido, obstinado y perverso en los vv. 160-176), pasando por Abraham, David, etc. (vv. 193-200). Estos versos, sin embargo, no son de pura alabanza al pueblo judío: mencionan también a Caín ${ }^{9}$ y a otros personajes bíblicos que desobedecieron a Dios (vv. 201-224). El público del auto sacramental en el Siglo de Oro sabe que el pueblo judío albergaba en él la posibilidad de traicionar a Dios. Esto se ve explicitado en los versos:

Esto está en muchos casos comprobado pues vemos de ellos la Escritura llena:

Ismael, Esaú y Rubén, testigos

a quien su error, de Dios hizo enemigos. (vv. 221-224)

posterior al nuestro (Mística y Real Babilonia, 1662), ambos se sitúan en Babilonia y cuentan con un gracioso llamado Zabulón que contrasta con la figura del piadoso Daniel, por lo que encontramos sus observaciones sumamente pertinentes para el estudio del auto de Castillo Solórzano.

9 Daniel: «[...] respondo que Caín el fratricida / fue, aunque causa parcial, el instrumento / de familia tan mala y tan perdida / que a la bondad de Dios opuesta, intenta / ser de su protección y auxilio exenta» (vv. 203- 208). 
En efecto, para que el público se encontrase reunido alabando el sacramento de la Eucaristía, la traición del pueblo judío había tenido que darse: la propia historia del cristianismo vista desde los ojos de un español del Siglo de Oro prueba que, a pesar de la existencia pasada de aquellos hebreos ejemplares de los que habla la Biblia, en algún momento el pueblo hebreo se degradó, convirtiéndose en asesino de Dios. El hecho de que Zabulón sea a su vez uno de los jefes de la tribu se inscribe en la misma lógica del discurso de Daniel, del que se desprende que algunos elementos del pueblo hebreo han traicionado a Dios desde sus inicios, deshonrando al «pueblo elegido». Se abre la posibilidad, para los espectadores, de que los judíos que ellos conocen hayan descendido justamente de este personaje, y no de aquellos hombres tan nobles y ejemplares como lo parecen ser Daniel y Nehemías. Vemos aquí cómo se cumple en el caso del auto de Castillo Solórzano lo mismo que señala Reyre al respecto de los autos de Calderón, en los que partimos

de la visión positiva (idealizada, incluso) del pueblo hebreo, observada en un primer momento dramático, la cual será destruida luego mediante evocaciones concretas y burlescas, las del judío, objeto de mofa, que constituye la versión trivializada del hebreo bíblico. (1998: 15-16)

Cabe resaltar tal vez que el resto de «hebreos» que aparecen en el auto (Daniel, Nehemías como más importantes, Helí y Eliazar como secundarios) no tienen en realidad una personalidad propia o rasgos que los distingan realmente los unos de los otros: son tan solo hebreos piadosos, ecos de un pasado remoto que ya no existe en la actualidad. Daniel en otro tipo de auto hubiera podido llamarse «conciencia divina» o algo por el estilo. Esto trae como consecuencia que el personaje del gracioso sobresalga en contraposición a ellos, acentuando el contraste y la vigencia de la figura de Zabulón como representante del «judío» en el tiempo presente.

Para terminar, detengámonos un momento en el título completo del auto: Auto sacramental historial alegórico: El fuego dado del cielo. El adjetivo «historial» (es decir, lo perteneciente a la historia, según Autoridades) se explica porque el argumento del auto procede de la Biblia, pero también porque a nivel alegórico el auto dramatiza, a través de los personajes escogidos y las decisiones que estos toman, la historia de la Alianza de los hombres con Dios y la Salvación: Dios eligió a un pueblo y lo protegió, pero algunos de sus elementos lo traicionaron y no reconocieron al Mesías cuando este vino a la tierra, como Zabulón no reconoce en «el agua crasa» el fuego sagrado, la prueba de que la Alianza entre Dios y su pueblo sigue viva. La incredulidad de Zabulón prefigura, por una parte, lo que vendrá después, historia harto conocida para el público del auto: cuando viene el Mesías, los judíos no lo reconocen y lo condenan a muerte. Pero al mismo tiempo 
dramatiza en clave alegórica la «ignorancia» de los protestantes, quienes niegan el misterio de la transubstanciación, razón de ser del auto sacramental ${ }^{10}$. En efecto, la analogía entre el fuego y el pan se va construyendo desde el momento en que Zabulón entra en el pozo y, al ver el fuego, lo compara con «nieve o leche cuajada» (vv. 940-941), «un cazo de almidón [...] frío» (v. 942) e incluso «maná del desierto» (v. 944), énfasis que contrasta con la descripción de «líquido espeso» que le da la Biblia en II Macabeos 1, 20. Paralelamente, el texto hace énfasis en que Zabulón «muere de temor» (v. 914) y sale del pozo «haciendo de frío roscas como galgo» (v. 949), sin poder creer que aquello que ha visto sea el fuego sagrado (o el cuerpo de Cristo). Dice Nehemías, reprendiéndolo: «Si todos tu fe tuviesen [...] iQué esperanza de un hebreo / a quien su Dios ha sacado / de un cautiverio pesado!» (vv. 1030-1032).

La responsabilidad de exponer claramente la relación entre el argumento del auto y el asunto recae en Nehemías, quien, después de reprender a Zabulón, inicia una serie de alabanzas en las que compara explícitamente el fuego encontrado con la presencia de Cristo en el pan y el vino:

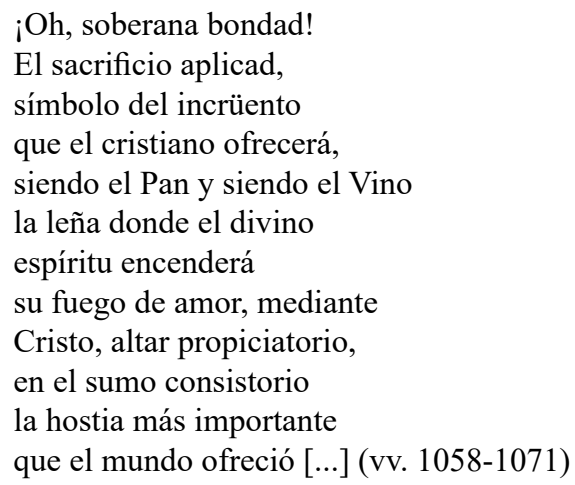

De esta manera, a pesar de los elementos de la comedia que se le han aplicado (el enredo amoroso, la figura del gracioso Zabulón), el auto de Castillo Solórzano no pierde de mira el asunto: celebrar la Eucaristía, porque los elementos cómicos se mantienen al servicio de la alegoría.

Nos gustaría concluir entonces con un comentario sobre el alcance del contenido teológico del auto, que si bien tiene algunos puntos débiles en comparación con los autos de Calderón, sí que retoma algunos elementos centrales de la fe cristiana: ese fuego que no reconoce Zabulón representa a un dios único, sí, pero es un dios impersonal y lejano, que da unas normas de vida (que fueron por cierto

\footnotetext{
10 Como señalan Ignacio Arellano y Enrique Duarte, «el tema de todo auto sacramental es la salvación humana por medio de la Eucaristía y la presencia de Dios en la Sagrada Forma» (2003: 8).
} 
muy importantes para la civilización hebrea), pero que es también un dios implacable con quienes no siguen estas normas. El niño que aparece al final, en cambio, representa la nueva visión de la divinidad que aparece con la figura de Cristo. Ya no es el dios único e impersonal, el Cristo le da una cara y un cuerpo a Dios. Pero además, Castillo Solórzano nos habla de la trinidad: el niño (el hijo), las brasas de fuego en sus manos (el padre) y los rayos de luz (el espíritu santo). El niño representa la llegada de ese Mesías que los judíos no reconocen, y que los protestantes se niegan a ver encarnado en la Eucaristía.

¿Entendía el pueblo todo esto? No lo sabemos a ciencia cierta, aunque coincidimos con Bruce Wardropper en que el éxito de los autos debe sustentarse también en la posibilidad de que el público estuviese «más enterado de cosas de teología que el de hoy en día» y que fuese capaz de pensar en términos alegóricos, sin que esto signifique que no tuviera que «esforzarse por comprender las ideas presentadas en el drama del Corpus» (1967: 92-95). Y en caso de no ser capaces de asimilarlo todo, es innegable que el «cierto clima de ideas» en el que habían crecido les permitiría descubrir algunas nociones básicas sobre la Salvación, el Pecado o la presencia de Jesucristo en la Eucaristía (1967: 94). En el caso específico del auto de Castillo Solórzano, que los judíos, glotones y limitados, no se dieron cuenta de que Jesús era el hijo de Dios, eso sí que lo entendían; y que un hombre casado que desea a otra mujer sea castigado por ello, también. Retomando a Hess (1976: 298-299), podemos concluir que la comicidad está condicionada por la idea didáctica y alegórica en este auto sacramental, y resulta además un recurso muy adecuado para plasmar en la escena algunos elementos centrales de la doctrina cristiana, pero también, sin lugar a dudas, del casticismo español (Rodríguez Puértolas 1970: 112).

\section{BiBLIOGRAFÍA}

Arellano, Ignacio, y Duarte, Enrique (2003). El auto sacramental. Madrid: Ediciones del Laberinto.

Castillo Solórzano, Alonso de (2000). El fuego dado del cielo. Edición, prólogo y notas de Gabriel Maldonado Palmero. Huelva: Hergué Editorial.

FLeCNIAKosKa, Jean-Louis (1961). La formation de l'auto religieux en Espagne avant Calderón (1550-1635). Montpellier: Imp. P. Dehan.

García Ruiz, Víctor (1994). «Elementos cómicos en los autos de Calderón: función y sentido». Criticón, 60, pp. 129-142. [En línea]. < http://cvc.cervantes.es/literatura/ criticon/PDF/060/060_126.pdf $>$ [consulta: 25-05-2017].

Garrot ZambranA, Juan Carlos (2001). «Fonction du gracioso dans l'auto sacramental Mistica y real Babilonia de Calderón de la Barca». En Pierre Civil (coord.), Écriture, pouvoir et société. Hommage du CRES à Augustin Redondo. Paris: Publications de la Sorbonne, pp. 329-338. 
Herodoto (2015). Historia. Libro III (Talia). Edición, prólogo y notas de José Floristán M. Madrid: Dykinson.

Hess, Rainer (1976). El drama religioso románico como comedia religiosa y profana. Madrid: Gredos.

Maldonado Palmero, Gabriel (2000). «Análisis crítico del texto». En Alonso de Castillo Solórzano, El fuego dado del cielo. Huelva: Hergué Editorial, pp. 13-109.

ReYre, Dominique (1998). Lo hebreo en los autos sacramentales de Calderón. Kassel: Edition Reichenberger.

Rodríguez PuÉrtolas, Julio (1970). «La transposición de la realidad en los "autos sacramentales" de Lope de Vega». Bulletin Hispanique, 1-2, pp. 96-112.

WARDROPPER, Bruce (1967). Introducción al teatro religioso del Siglo de Oro. Salamanca: Ediciones Anaya.

Recibido: $12 / 10 / 2017$

Aceptado: 25/11/2017

Alegoría y COMicidad en el auto SaCramental de Alonso de Castillo Solórzano EL FUEGO DADO DEL CIELO

RESUMEN: El fuego dado del cielo parece ser, hasta la fecha, el único auto sacramental que escribiera Alonso de Castillo Solórzano. Se trata de un auto de tema bíblico que incorpora diversos elementos de la comedia, como el enredo amoroso y la figura del gracioso Zabulón. En este artículo, comentaremos la manera en la que Castillo Solórzano recurre a dichos elementos con fines alegóricos y didácticos, manteniendo siempre la situación cómica al servicio de la alegoría.

PALABRAS ClAVE: alegoría, comedia, gracioso Zabulón, enredo.

\section{Allegory and Humour in Alonso de CASTillo Solórzano’s Auto EL FUEGO DADO DEL CIELO}

ABSTRACT: El fuego dado del cielo seems to be, to date, the only sacramental auto written by Alonso de Castillo Solórzano. It is a biblical auto that incorporates diverse themes of Spanish comedy such as the romantic-entanglement and the humorous Zabulón figure. In this article, we will comment on the way Castillo Solórzano turns to said elements with an allegorical and didactic end, keeping comedy at the service of allegory.

KeYwords: Allegory, comedy, humorous Zabulón, romantic-entanglement. 


\section{EDAD DE ORO}

Revista de Filología Hispánica XXXVI








\section{Edad de Oro. Revista de Filología Hispánica}

ISSN: 0212-0429

Dirección:

Teodosio Fernández

Secretaría y edición:

José Ramón Trujillo

Consejo de redacción:

Manuel Piqueras

Blanca Santos

Admisión de originales:

María Jesús Zamora

Edad de Oro

Departamento de Filología Española

Universidad Autónoma de Madrid

28049 Madrid (España)

Tfno.: +0034914974090

correo: mariajesus.zamora@uam.es

Distribución, suscripción y venta:

Servicio de Publicaciones de la UAM

Universidad Autónoma de Madrid

28049 Madrid (España)

Intercambio de publicaciones:

Biblioteca de la Facultad de Filosofía y

Letras (UAM)

Universidad Autónoma de Madrid

28049 Madrid (España)
Comité científico internacional:

Carlos Alvar (Univ. de Ginebra)

Ignacio Arellano (Univ. de Navarra)

Javier Blasco (Univ. de Valladolid)

Alberto Blecua (UAB)

Jean Canavaggio (Univ. de París X)

Laura Dolfi (Univ. de Turín)

Aurora Egido (Univ. de Zaragoza)

Víctor García de la Concha (RAE)

Luciano García Lorenzo (CSIC)

Joaquín González Cuenca (Univ. de

Castilla-La Mancha)

Agustín de La Granja (Univ. de Granada)

Begoña López Bueno (Univ. de Sevilla)

Michel Moner (Univ. de Toulouse III)

Joan Oleza (Univ. de Valencia)

Alfonso Rey (Univ. de Santiago)

Lina Rodríguez Cacho (Univ. de Salamanca)

Leonardo Romero Tobar (Univ. de Zaragoza)

Aldo Ruffinatto (Univ. de Turín)

Lía Schwartz (City University of New York)

Han colaborado en este volumen:

Departamento de Filología Española (UAM)

Facultad de Filosofía y Letras (UAM)

Edad de Oro se recoge, entre otras, en las siguientes bases de datos: SCOPUS, MLA Database, HLAS, Latindex, PIO-Periodical Content Index, ISOC, Dialnet, MIAR, ERIH Plus, DICE, Sumaris CBUC, Ulrich's. Se encuentra evaluada en CIRC: A; MIAR difusión ICDS live 2016: 10.0; INRECH; SCImago Journal \& Country Rank: H Index 3, SJR SCImago Journal \& Country Rank 0,1, Q4; RESH índice de impacto: 0.041; ERIH: A INT1; Carhus Plus+2014: C. 